\title{
A classical model of educational cooperation in Human Anatomy: the Table Leaders
}

\author{
A.R.W. Pinto-Souza, G. Pérez-Arana, C. Firetto-Saladino, C. Carrasco-Molinillo, \\ A. Ribelles-García, J.A. Prada-Oliveira \\ Department of Human Anatomy and Embryology, Faculty of Medicine, University of Cádiz, Spain
}

[Received: 16 July 2018; Accepted: 12 November 2018]

\begin{abstract}
This project has been developed for many years in the Human Anatomy courses. Its good outcomes have been confirmed by years of evidence of excellent results obtained through the learning of Human Anatomy. This method of teaching and learning as one allows students who are taking Human Anatomy classes to receive practical training in small groups and transmit it to their colleagues in the practical training established in the Medical degree. Table Leaders feel rewarded as they learn to speak in public, regularly transmitting the knowledge obtained, and by having to be up to date with their studies. These are all aspects that help, not only the Table Leaders process of learning, but also that of their colleagues, who see closely and carefully anatomical details that help them understand the subject. This method of supporting practical training is always under the supervision of the teacher who develops the practical classes. These Leaders used to pass the test without additional problems. Thus the note was significantly increased versus the class colleagues. (Folia Morphol 2019; 78, 3: 626-629)
\end{abstract}

Key words: medical education, anatomy learning, peer-teaching, human anatomy

\section{INTRODUCTION}

Human Anatomy is one of the subjects with the highest workload of the first years of the Medical degree $[2,3]$. We have an important advantage: the initial receptiveness of students to these contents [11]. Students arrive to the university with a preconceived idea that Anatomy will start their path of becoming doctors. For that reason, they will have to work hard and learn it well to ensure future success. Furthermore, from all the courses taken in the first years, they probably see Anatomy as being one of the most "Medicine-related" $[3,6]$, and link us teachers to the clinical image they expect of doctors. These details are surely a key in our favour that allows us to relate students to contents that are "tougher" than what they expect.
Our practical activities, adequate to the teaching materials we have, take place in specific facilities at the Anatomy Department. Our specific workshops take place at the dissection classrooms and at the anatomic museum. But besides these teaching peculiarities, our practical training is programmed and coordinated with the theoretical contents, in the same way as it should be done in any other subject. The peculiarity resides in the fact that in these practical activities we use models (dissected corpses, plastinated corpses or materials and plastic commercial models) that need to be thoroughly defined and discussed $[7,9,10]$. During the activities, a detailed description of the used materials is made, using the concepts that were previously taught in theoretical classes. Nonetheless in these descriptions

Address for correspondence: J.A. Prada-Oliveira, MD, PhD, Department of Human Anatomy and Embryology, Faculty of Medicine, Plaza Fragela s/n, University of Cádiz, Cádiz, 11003, Spain, tel: +34 956015817, fax: +34 956015254, e-mail: arturo.prada@uca.es 
it is important to emphasize, in small details, reliefs, markings and spatial relations that the structures have between themselves. This needs to be done in small groups, where someone will guide the explanation but where everyone will have the chance to speak, comment and ask questions $[8,15]$. This would be impossible with a specific teacher because there would not be enough time to create small groups of 6-7 students. It goes without saying that it is impossible to work with the corpse when there are a large number of students who are not able to follow a detailed explanation because they cannot analyse the model in deep.

That is why we decided to adopt the Table Leaders concept. This means that students who are taking the Anatomy course will help explain the contents of the practical activities to their peers [15]. In other words, as the students get theoretical knowledge, these Table Leaders are also going to receive a special training in some practical activities that are designed for them. Later on, these students will reproduce those contents, the anatomical details studied, to their peers [8]. In this sense, students can engage anatomical understandings to their personal abilities [1]. These activities were also perceived to enhance motivation and improve understanding of the subject to students, both Table Leaders and passive peers [14].

This Table Leaders dynamic is not a new topic to our Anatomy Department [5]. Most of the teachers who work today in this department do not know when this type of work started. This heritage came from former teachers who we knew had good results and we saw it being developed when we were students of that particular subject. We continue to promote this method due to the good results that were traditionally obtained. Similar experiences were developed in other health science studies, as nursing, physiotherapy, etc. [13].

\section{MATERIALS AND METHODS}

The Human Anatomy subjects in the Faculty of Cádiz are present in the two first courses of the grade. Every course has 160 students. All students have an open option to be part on the selection as Table Leader.

We studied the results obtained by the student who received the preliminary subject "Basic Human Anatomy", which was developed in the first trimester. The analysis of the results and improvement was observed during the late five academic courses.

\section{Selection of the Table Leaders}

From the voluntary students, we select as many Table Leaders as is recommended for the tasks that are expected for that academic year. Usually, based on our experience, about 5 students for each practical activity group (40-50 students) are selected. It is important that this selection is made among motivated students. For this purpose, we explain during the class, the missions, duties and the additional work that they will have to perform. After giving this information to the entire class, as to avoid exclusions, all those interested will write an exam that takes place at the Anatomy Department.

Obviously, this exam does not include anatomical knowledge, which they still do not possess. However, we do value their capacity to speak correctly and to describe complex 3-dimensional structures. We observe how they convey ideas, and how they express themselves. All these will bring value to the job that they will later have to perform. For this, we ask them to describe a bone or an articulation using any of the models available at the Anatomy Department. We reinforce to them that we do not value possible inaccuracies. We ask them to express themselves calmly as they would do with their peers in order to explain any doubts raised.

The fact that this process is open and not excluding anyone, is very important. As we explain in class, the Table Leaders work is rewarded in the final anatomy course grade. Although this will not guarantee passing the subject as the passing criteria is much more demanding. But it might be possible to add some decimals to the final grade, which is very important in the Medical Degree in order to obtain a better qualification for the MIR exam (in Spanish "Médico Interno Residente", postgraduate access to Residency) and access to a residency. Of course, their biggest profit will come from studying the subject deeper and this additional effort is seen in both the acquired knowledge and the exam performed.

\section{Practical activities preparation}

Before performing a practical activity with all the anatomy course students, the teacher usually prepares a specific session for the Table Leaders. In this, they see the contents that will be later developed in the practical activities with the rest of the groups. The material to be used is prepared. The teaching contents seen in class and the data that is essential to be transmitted to the students are analysed. Any questions the Table Leaders might have are answered. 
This is important because if the wrong data is not corrected it could later be passed on to the entire class. The unsolved questions will not later be clarified by them. A good Table Leaders' session will facilitate and assure that during the activities with the larger groups the contents are well transmitted, without mistakes, as well as be time efficient and correctly depict all the details present in the models and corpses.

For this to happen, there are different methods adopted by the different teachers. Some prefer to bring sketches of the practical activity so that the Table Leaders have a reference and don't miss important details.

\section{The practical class}

In the days scheduled by the university, the groups of students that will be involved in the practical activities are called to the premises of the Anatomy Department. According to the work previously developed with the Table Leaders they will either go to the dissection room, if it is with corpse material, or to the anatomical museum, if it is with plastic material. The Table Leaders will take care of the group according to the division previously made. Grouped around the leader, the students will go through all the different tables where the pieces to be studied are located. This creates a circuit of 4 or 5 workstations with the materials that will be used in the activity.

The Leaders will develop the contents with explanations and will detail the important aspects that should be remembered by the students. In several cases, the Table Leaders will try to stimulate their peers by asking questions, provoking a non-passive environment where students would only receive the data, repeating in a certain way what they have already seen in class.

We, the teachers, follow closely the Table Leaders' explanations, as promoted for other authors [4]. We correct the incorrect data they might be saying, we answer their doubts or those of some of the other students which could put them in a difficult situation in complex subjects. The teachers are there in order to solve any difficult circumstance that could arise. As in other experience, with the participation of interprofessional members in teaching activities, the teacher must improve understanding any mistake and clinical application of the topics [12].

\section{Evaluation of the experience}

A final questionnaire was applied to all the students (Table Leaders and general students) of the past three
Table 1. Survey for activity assessment

\begin{tabular}{ll}
\hline Question 1 & $\begin{array}{l}\text { What do you think about the role of Table Leaders? Is it } \\
\text { a valuable model that increases the quality of anatomy } \\
\text { practical classes? }\end{array}$ \\
Question 2 & $\begin{array}{l}\text { Did you find comfortable with your role (Table Leaders or } \\
\text { alumni) in these practical lessons? }\end{array}$ \\
Question 3 & $\begin{array}{l}\text { Did you resolve your anatomical doubts with your col- } \\
\text { leagues? }\end{array}$
\end{tabular}

courses. The questions were related to the agreement with this docent model (Table 1). A Likert scale (from 0 to 5 graded) was used to ask for the items. To understand the different perception, the questions were separately analysed for the Table Leaders and the general alumni.

\section{Statistical analysis}

Moreover, we analysed the final results in the subject, obtained for both groups (general students versus Table Leaders). To this purpose, comparisons between the groups were performed using the ANOVA test. Once the non-parametric samples character was stablished, these data were analysed with U-Mann-Whitney test and $p<0.05$ was considered statistically significant. Measurement data were expressed as mean \pm standard error of the mean (SEM). All statistical analyses were performed using SPSS statistical software, version 24.0.

\section{RESULTS}

Generally, both general alumni and Table Leaders found this model useful; they considered this system increased the quality of practical lessons $(4.34 \pm 0.75)$. The value was not significantly different between the three analysed courses. In other sense, the perceived quality of the activities and model was similar between the both groups. The Table Leaders considered that the role improved the anatomy learning $(4.69 \pm 0.6)$ versus the general alumni $(4.16 \pm 0.98)$.

Both, Table Leaders and remnant alumni found comfortable with the role of other colleagues during the lessons. All groups found a relaxed and non-stressful situation, as question two signed ( $4.23 \pm 0.95)$; with no important differences between groups and courses.

The transverse relationship between students helped to resolve doubts, as the third question pointed $(3.9 \pm 0.6)$. But, as we considered, the help of a presently professor must be assured. All the students, grouped or isolated by courses or role, signed similar data. 
Table 2. Final note of the alumni

\begin{tabular}{lllll}
\hline Course & $\mathbf{2 0 1 5 / 1 6}$ & $\mathbf{2 0 1 6 / 1 7}$ & $\mathbf{2 0 1 7 / 1 8}$ & Median \\
\hline Table Leaders & $8.3 \pm 1.1$ & $8.5 \pm 0.9$ & $8.7 \pm 0.6$ & $8.5 \pm 0.7$ \\
General Alumni & $6.7 \pm 1.9$ & $7.0 \pm 1.6$ & $6.9 \pm 1.8$ & $6.8 \pm 1.8$ \\
\hline
\end{tabular}

The results of the test were graded ' 0 to 10 points', where 0 represents the failed test and $1-$ the recognised excellence. Data are presented as median \pm standard error of the mean of the final note, once the alumni had passed the subject test.

About the final results in the tests of the subject, we analysed the results of both groups in the past 3 years. The final note of the alumni was presented in the Table 2. General alumni showed a severe decrease of the note versus the Table Leaders; and this tendency was maintained in the studied period.

\section{DISCUSSION. THE FINAL "GRADE"}

As we already discussed, the Table Leaders have a small compensation towards their final grade. Usually, it is included in the student record as an additional aspect that is added to the final grade obtained in the examinations and activities performed during the year.

In general, the best results were seen by the exam performance, where the Table Leaders had excellent grades. We considered that this was the result of the yearlong continuous study, which logically turned into a better knowledge of the contents. The Table Leaders showed 1.7 - over 10 - versus the general alumni (Table 2).

We confirmed some mentioned aspect. The transverse relationship between Leaders and their colleagues favoured the learning process. This relation was stablished in a non-stressful situation. But both groups - general and leaders - gave a minor value to the final resolutions of doubts. The permanent presence of the professor must reduce the uncertainty during the leader explanation.

A last aspect to be pointed out is the way Table Leaders get linked to the subject. A vocation towards anatomy has frequently come from former Table Leaders, who later on became interns (nowadays called Collaborator Student) in the Anatomy Departments. In several cases, it is a way to get connected to our subject, up to the point where some of those students will come back to our laboratories to work on their doctoral thesis.

\section{CONCLUSIONS}

Finally, we consider this is a good strategy to involve all the students in the learning of the anatomy. Moreover, the Table Leaders obtained an important improvement in their anatomical knowledge, which could be an enhanced basis for the clinical matters.

\section{REFERENCES}

1. Anstey LM. "Applying anatomy to something I care about": Authentic inquiry learning and student experiences of an inquiry project. Anat Sci Educ. 2017; 10(6): 538-548, doi: 10.1002/ase.1690, indexed in Pubmed: 28376275.

2. Bergman EM, van der Vleuten CPM, Scherpbier AJ. Why don't they know enough about anatomy? A narrative review. Med Teach. 2011; 33(5): 403-409, doi: 10.3109/0142159X.2010. 536276, indexed in Pubmed: 21355704.

3. Böckers A, Jerg-Bretzke L, Lamp C, et al. The gross anatomy course: an analysis of its importance. Anat Sci Educ. 2010; 3(1): 3-11, doi: 10.1002/ase.124, indexed in Pubmed: 20058224.

4. Chiu M. Adapting teacher interventions to student needs during cooperative learning: how to improve student problem solving and time on-task. Am Edu Res J. 2016; 41(2): 365-399, doi: 10.3102/00028312041002365.

5. Drake RL, McBride JM, Lachman N, et al. Medical education in the anatomical sciences: the winds of change continue to blow. Anat Sci Educ. 2009; 2(6): 253-259, doi: 10.1002/ ase.117, indexed in Pubmed: 19890982.

6. Estai M, Bunt $S$. Best teaching practices in anatomy education: A critical review. Ann Anat. 2016; 208 : 151-157, doi: 10.1016/j.anat.2016.02.010, indexed in Pubmed: 26996541.

7. Jones DG, Whitaker MI. Engaging with plastination and the Body Worlds phenomenon: a cultural and intellectual challenge for anatomists. Clin Anat. 2009; 22(6): 770-776, doi: 10.1002/ca.20824, indexed in Pubmed: 19585569.

8. King A. Enhancing Peer Interaction and Learning in the Classroom Through Reciprocal Questioning. Am Edu Res J. 1990; 27(4): 664, doi: 10.2307/1163105.

9. Kuan EC, Badran KW, Passy V, et al. Medical students' comfort levels with performing the basic head and neck examination in practice: follow-up during the core clerkship year. J Surg Educ. 2015; 72(1): 117-121, doi: 10.1016/j. jsurg.2014.06.007, indexed in Pubmed: 25168714.

10. Kumar RK, Freeman B, Velan GM, et al. Integrating histology and histopathology teaching in practical classes using virtual slides. Anat Rec B New Anat. 2006; 289(4): 128-133, doi: 10.1002/ar.b.20105, indexed in Pubmed: 16865702.

11. Lazarus L, Sookrajh R, Satyapal KS. Reflective journals: unmasking student perceptions of anatomical education. Folia Morphol. 2017; 76(3): 506-518, doi: 10.5603/ FM.a2017.0019, indexed in Pubmed: 28248411.

12. Luetmer MT, Cloud BA, Youdas JW, et al. Simulating the multi-disciplinary care team approach: Enhancing student understanding of anatomy through an ultrasound-anchored interprofessional session. Anat Sci Educ. 2018; 11(1): 94-99, doi: 10.1002/ase.1731, indexed in Pubmed: 28914990.

13. Mahajan R, Mohammed CA, Sharma M, et al. Interprofessional Education: An Approach to Improve Healthcare Outcomes. Indian Pediatr. 2018; 55(3): 241-249, indexed in Pubmed: 29629699.

14. Sahota M, Leung B, Dowdell S, et al. Learning pathology using collaborative vs. individual annotation of whole slide images: a mixed methods trial. BMC Med Educ. 2016; 16(1): 311, doi: 10.1186/s12909-016-0831-x, indexed in Pubmed: 27955651.

15. Webb N. Peer interaction and learning in small groups. Int J Educ Res. 1989; 13(1): 21-39, doi: 10.1016/08830355(89)90014-1. 